\title{
Comparison of different voltage dip detection techniques
}

\author{
M. A. Alonso, J. F. Sanz, J. Sallán and J. L. Villa \\ CIRCE Foundation - University of Zaragoza. Electrical Engineering Department. C/ María de \\ Luna 3, 50018 Zaragoza. Tel. Nr. (+34) 976762403. \\ e-mail: malonso7@unizar.es,jfsanz@unizar.es, jsallan@unizar.es, jvilla@unizar.es
}

\begin{abstract}
To accurately determine the beginning and the end of voltage sags is very important for the actuation of a system that is connected to the grid and must have ride-through capability. This paper analyses four voltage sag detection methods, comparing both detection speed and reliability, not presenting false detections and providing a consistent signal during all the gap duration. In particular, it has been analysed the behaviour of the detection methods when voltage waveforms present harmonics due to power electronics switching.
\end{abstract}

Key words: Voltage dips, Voltage sag detection, Power quality, Wind energy.

\section{Introduction}

The increase in renewable energy use in electrical energy generation makes necessary the compliance with some technical requirements in order not to compromise the operation of the electric system.

These connection requirements affect all the aspects related to the quality of the energy sent to the grid [1] and the behaviour of the system when grid perturbations occur. Voltage sags are one of the many power quality related problems the industrial process sector has to face, and they are one of the most severe. They consist on a reduction of the voltage at a customer position with duration between one cycle and half a second. [2].

This paper compares the behaviour of four voltage sag detection methods when facing three phase faults, according to Spanish Operation Procedure 12.3.

The aim of the paper is to determine the best detection method to be used in the control of the grid connection inverter of a variable-speed squirrel-cage wind turbine connected to a weak grid, in order to provide it with voltage sag ride-through capability.

\section{Simulated methods}

Several voltage detection methods have been documented for use in various voltage compensation schemes. In this paper, the following methods are simulated and evaluated.

\section{a) Appling the Fourier Transform to Each Phase}

This method gives the amplitude and phase of the main component of the utility voltage, but its main drawback is the need for at least half period $(10 \mathrm{~ms})$ in order to have an accurate result, which generates a significant delay in the response of the system to a voltage sag.

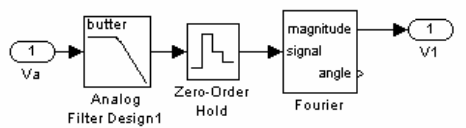

Fig. 1. Matlab implementation of the Fourier Method.

b) Numerical Matrix Sag Detection Method [3]

The method calculates the magnitude and phase of the different harmonics present in the supply voltages. It is applied to each phase independently and as thus can monitor the start or end of the sag, its depth and any phase jump.

In order to provide a unique solution, the number of equations to be solved is twice the number of harmonics detected in the supply. For instance, if only the 
fundamental and the fifth harmonics are considered, the equations to be used are:

$$
\begin{aligned}
& v_{\text {present }}=\left|V_{1}\right| \cos \left(\omega_{1} t+\phi_{1}\right)+\left|V_{5}\right| \cos \left(\omega_{5} t+\phi_{5}\right) \\
& v_{\text {past } 1}=\left|V_{1}\right| \cos \left(\omega_{1} t-\omega_{1} T+\phi_{1}\right)+\left|V_{5}\right| \cos \left(\omega_{5} t-\omega_{5} T+\phi_{5}\right) \\
& v_{\text {past } 2}=\left|V_{1}\right| \cos \left(\omega_{1} t-2 \omega_{1} T+\phi_{1}\right)+\left|V_{5}\right| \cos \left(\omega_{5} t-2 \omega_{5} T+\phi_{5}\right) \\
& v_{\text {past } 3}=\left|V_{1}\right| \cos \left(\omega_{1} t-3 \omega_{1} T+\phi_{1}\right)+\left|V_{5}\right| \cos \left(\omega_{5} t-3 \omega_{5} T+\phi_{5}\right) \\
& {\left[\begin{array}{c}
V_{\text {present }} \\
V_{\text {past } 1} \\
V_{\text {past } 2} \\
V_{\text {past } 3}
\end{array}\right]=\left[\begin{array}{cccc}
1 & 0 & 1 & 0 \\
\cos \omega_{1} T & \sin \omega_{1} T & \cos \omega_{5} T & \sin \omega_{5} T \\
\cos 2 \omega_{1} T & \sin 2 \omega_{1} T & \cos 2 \omega_{5} T & \sin 2 \omega_{5} T \\
\cos 3 \omega_{1} T & \sin 3 \omega_{1} T & \cos 3 \omega_{5} T & \sin 3 \omega_{5} T
\end{array}\right]\left[\begin{array}{c}
\left|V_{1}\right| \cos \phi_{1} \\
\left|V_{1}\right| \sin \phi_{1} \\
\left|V_{5}\right| \cos \phi_{5} \\
\left|V_{5}\right| \sin \phi_{5}
\end{array}\right]}
\end{aligned}
$$

Solving equation (5), the magnitude and phase of the different harmonics can be determined.

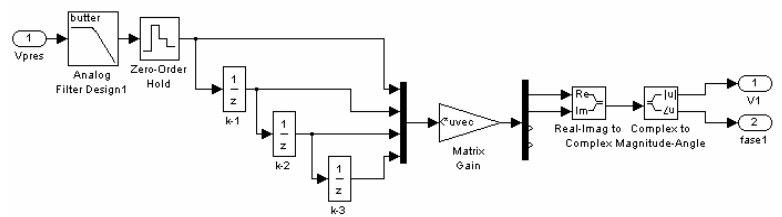

Fig. 2. Matlab implementation of the Matrix Method.

\section{c) Peak Value Evaluation Method [4]}

Assuming that input voltage $v_{i}(t)$ is given by

$$
v_{i}(t)=V_{p} \sin (\omega t)
$$

If $v_{i}(t)$ is sent to a $90^{\circ}$ phase shift circuit, then

$$
v_{i}^{\prime}(t)=V_{p}^{\prime} \cos (\omega t)
$$

is obtained.

The two signals are a pair of orthogonal functions. If they are sent to two separate multipliers and squared, it is easy to obtain the square of the input voltage peak value.

$$
v_{0 a}(t)=V_{p}^{2} \sin ^{2}(\omega t)+V_{p}^{2} \cos ^{2}(\omega t)=k V_{p}
$$

In order to measure the peak value, the signal $v_{0 a}(t)$ is fed to square root circuit.

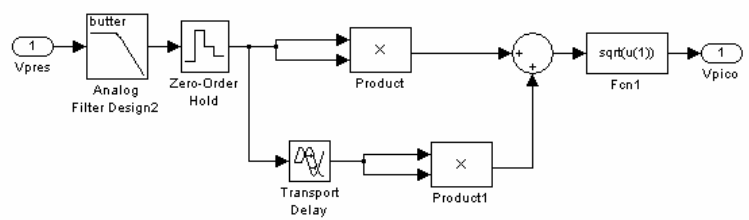

Fig. 3. Matlab implementation of the Peak-Value Method.

\section{d) RMS Value Evaluation Method [5]}

This method gives a correct measure of the evolution of the observed magnitude since it expresses the energy content of the signal.
If $\mathrm{N}$ samples are taken within a cycle, the RMS value at time $\mathrm{k}$ is given by:

$$
V_{r m s}[k]=\sqrt{\frac{1}{N} \bullet \sum_{n=0}^{N-1} v^{2}[k-n]}
$$

where

$$
\sum_{n=0}^{N-1} v^{2}[k-n]=v^{2}[k]-v^{2}[k-N]+S[k-1]
$$

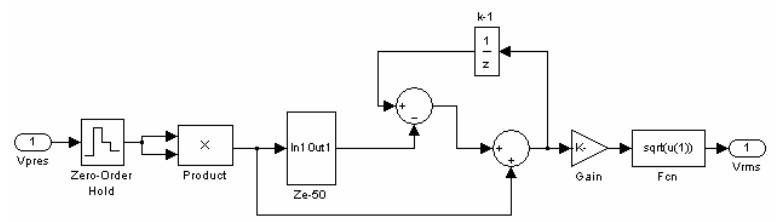

Fig. 4. Matlab implementation of the RMS-Value Method.

\section{Detection method comparison}

The selected system must be able to detect voltage sags as quickly as possible and be as immune as possible to the presence of harmonics in the grid voltage. Precision and fast detection are essential features for the detection method, in order for the system to ride through voltage sags.

Fig. 5 shows a three-phase voltage sag used in the simulations, which starts at $\mathrm{t}=0.2 \mathrm{~s}$ and lasts for $0.5 \mathrm{~s}$.

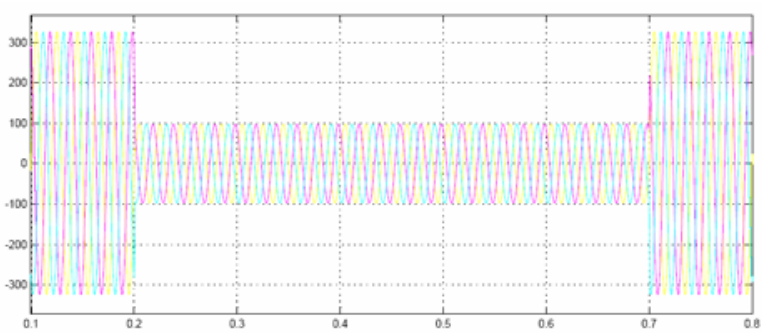

Fig. 5. Simulated three-phase sag.

Since the simulated system is connected to a weak grid, it is highly influenced by the harmonic content, and one of the goals of the paper is to determine which detection method is more robust.

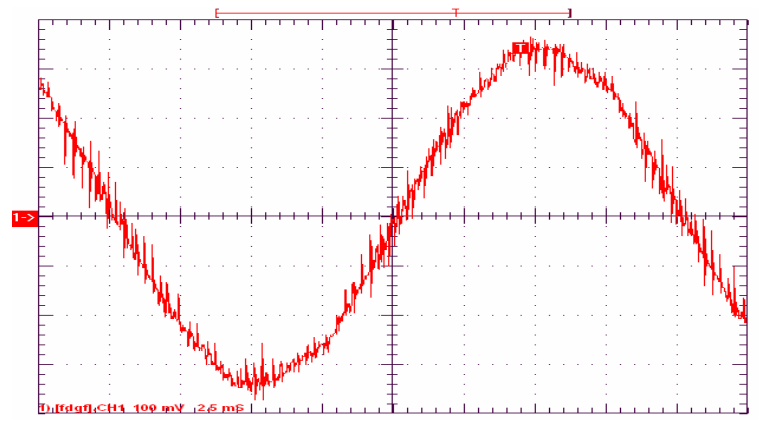

Fig. 6. Voltage at the connection point of the utility-side inverter. 
Fig. 6 depicts the signal obtained at the output of the utility-side inverter, with a $5 \mathrm{kHz}$ switching frequency, showing the distortion introduced by power electronics switching.

Several simulations have been carried out for different ripple magnitude in the voltage waveform:

- $\quad$ pure sinusoidal waveform

- waveform showing distortion introduced by a rectifying bridge.

- waveform showing a $5 \%$ ripple and the distortion introduced by a rectifying bridge.

- waveform showing a $10 \%$ ripple and the distortion introduced by a rectifying bridge.

- waveform showing a $20 \%$ ripple and the distortion introduced by a rectifying bridge.

Fig. 7 shows the voltage amplitudes calculated using the different methods in the third case (5\% ripple).

a)

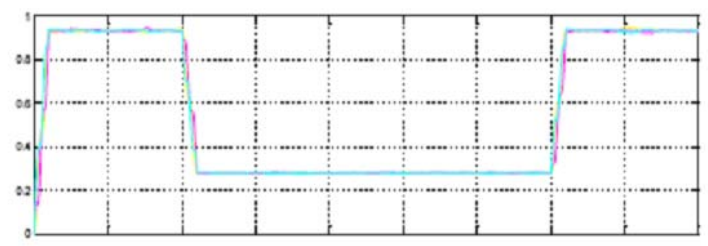

b)

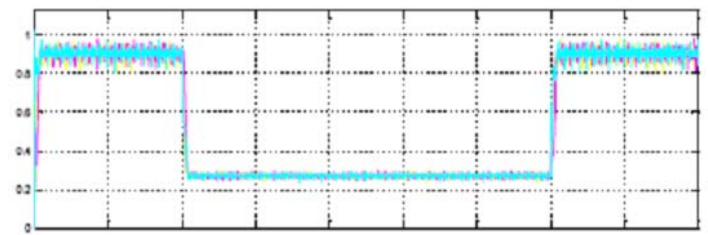

c)

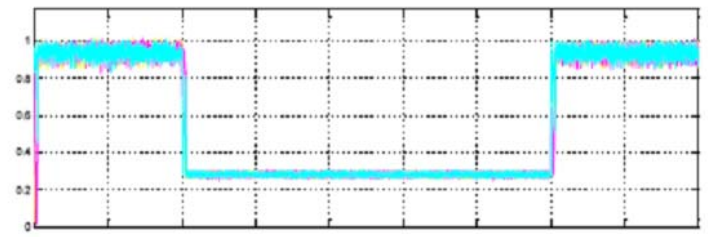

d)

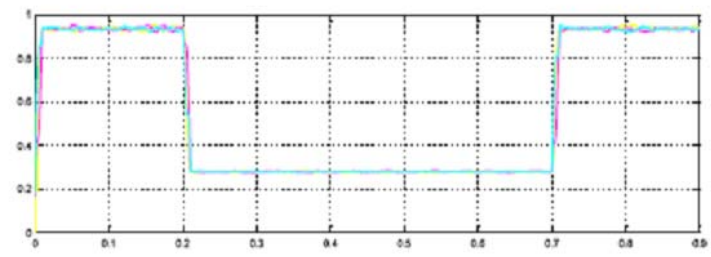

Fig. 7. Calculated phase voltages using the different methods: Fourier (a), Matrix (b), peak value (c) and RMS value (d).

It can be noticed that the Matrix method is the more sensitive to harmonics, so grid voltages have been filtered using a second order low-pass filter with a cut-off frequency of $100 \mathrm{~Hz}$.

Fig. 8 shows voltage amplitudes provided by the matrix method for the unfiltered voltage on a weak grid feeding a diode bridge. Large variation due to harmonics indicates the need for adequate filtering.

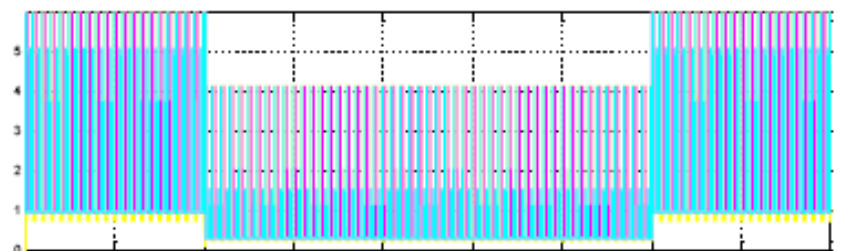

Fig. 8. Voltage amplitude in the three phases of a weak grid supplying a diode rectifier and suffering a three-phase voltage sag.

This filter introduces a delay of 2.3ms, which worsens significantly the detection time. However, Fig. 9 shows that, even considering this delay, the fastest detection method giving an accurate result is the matrix method.

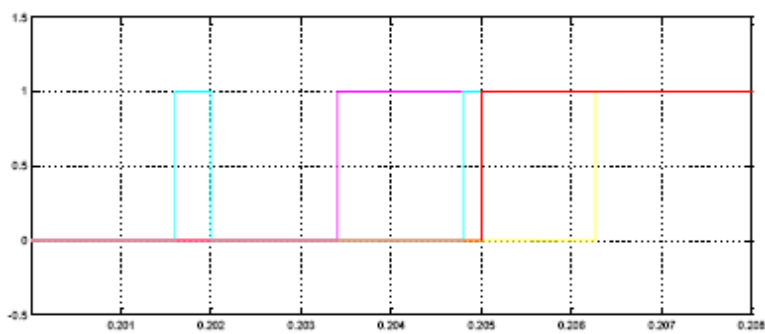

Fig. 9. Detection time for the different methods with a 5\% voltage ripple. Fourier (yellow), Matrix (pink), peak value (blue), RMS value (red).

The following table shows the voltage gap detection time and the required filters in order not to have incorrect detections.

\begin{tabular}{|c|c|c|c|c|c|}
\hline & Ideal & $\begin{array}{l}\text { Diode } \\
\text { bridge }\end{array}$ & 5\% ripple & $\begin{array}{l}10 \% \\
\text { ripple }\end{array}$ & $\begin{array}{l}20 \% \\
\text { ripple }\end{array}$ \\
\hline Fourier & $7.3 \mathrm{~ms}$ & $6.3 \mathrm{~ms}$ & $6.3 \mathrm{~ms}$ & $6.3 \mathrm{~ms}$ & $6.3 \mathrm{~ms}$ \\
\hline Matrix & $1.6 \mathrm{~ms}$ & $\begin{array}{l}2^{\text {nd }} \text { order, } \\
100 \quad \mathrm{~Hz} \\
\text { filter } \\
\mathbf{3 . 4 m s}\end{array}$ & $\begin{array}{lr}2^{\text {nd }} \text { order, } \\
100 \mathrm{~Hz} \\
\text { filter } \\
\mathbf{3 . 4 m s}\end{array}$ & $\begin{array}{lr}2^{\text {nd }} \text { order, } \\
100 \mathrm{~Hz} \\
\text { filter } \\
\mathbf{3 . 4 m s}\end{array}$ & $\begin{array}{lr}3^{\text {rd }} \text { order, } \\
100 \mathrm{~Hz} \\
\text { filter } \\
\mathbf{3 . 4 m s}\end{array}$ \\
\hline $\mathrm{V}_{\mathrm{p}}$ & $5.2 \mathrm{~ms}$ & $4.8 \mathrm{~ms}$ & $4.8 \mathrm{~ms}$ & $\begin{array}{l}2^{\text {nd }} \text { order, } \\
100 \mathrm{~Hz} \\
\text { filter } \\
\mathbf{3 . 4 m s}\end{array}$ & $\begin{array}{lr}2^{\text {nd }} \text { order, } \\
100 \mathrm{~Hz} \\
\text { filter } \\
\mathbf{3 . 4 m s}\end{array}$ \\
\hline $\mathrm{V}_{\mathrm{rms}}$ & $6.3 \mathrm{~ms}$ & $5.4 \mathrm{~ms}$ & $5 \mathrm{~ms}$ & $5.4 \mathrm{~ms}$ & $5.8 \mathrm{~ms}$ \\
\hline
\end{tabular}

Table 1. Three-phase voltage dip detection time.

\section{Conclusions}

The paper describes simulations of different voltage sag detection techniques and, among them, the best one is the matrix method, even having to use filtering, because it provides a consistent detection signal and gives the fastes response.

Besides, this method provides phase information, required for the inverter control algorithm in order to comply with Operation Procedure 12.3.

\section{References}

[1] S. A. Papathanassiou; N. D. Hatziargyriou. "Technical Requirements for the Connection of Dispersed Generation to the Grid”. Power Engineering Society Summer 
Meeting, 2001. IEEE Volume 2, 15-19 July 2001 Page(s):749 - 754 vol.2

[2] IEEE Recommended Practice for Monitoring Electric Power Quality, 1995. ANSI/IEEE Standard 1159.

[3] Chris Fitzer, Mike Barnes, and Peter Green. "Voltage sag detection technique for a dynamic voltage restorer”. IEEE
Transactions on industry applications, Vol. 40, No. 1, January/February 2004.

[4] Hui-Yung Chu, Hurng-Liahng Jou and Ching-Lien Huang, "Transient response of a peak voltage detector for sinusoidal signals". IEEE Transactions on industrial electronics, Vol. 39, No 1, February 1992.

[5] S.M. Deckmann, A.A. Ferreira, "About voltage sags and swells analysis”. IEEE 2002. 